\title{
Dirofilaria immitis in pinnipeds and a new host record
}

\author{
Ana Margarida Alho $^{1 \dagger}$, Inês Marcelino ${ }^{1 \dagger}$, Vito Colella ${ }^{2}$, Carla Flanagan ${ }^{3}$, Nuno Silva ${ }^{3}$, Jorge Jesus Correia ${ }^{1}$,
} Maria Stefania Latrofa ${ }^{2}$, Domenico Otranto ${ }^{2^{*}}$ and Luís Madeira de Carvalho ${ }^{1}$

\begin{abstract}
Background: Dirofilaria immitis is a mosquito-borne pathogen that is spreading worldwide, and the associated infection (i.e. dirofilariosis) is becoming a threat to animals and humans living in endemic areas. Little is known about the occurrence and risk of infection of D. immitis in pinnipeds. Here we report dirofilariosis by D. immitis in several pinniped species kept in captivity in Portugal.

Methods: Animals were housed in an oceanographic park located in Algarve, southern Portugal, a geographical area endemic for canine dirofilariosis. To assess the occurrence of D. immitis, blood was collected from the park's resident pinniped population, which consisted of 16 animals ( 5 common seals Phoca vitulina, 2 grey seals Halichoerus grypus, 3 California sea lions Zalophus californianus and 6 South African fur seals Arctocephalus pusillus pusillus). Dirofilaria immitis nematodes were detected by real-time PCR and by the presence of circulating antigens. In addition, modified Knott's technique was performed to detect circulating microfilariae. Necropsies and histopathological examination of two animals which died during the study were also conducted.

Results: Out of the 16 pinnipeds housed at the park, seven (43.8\%) were positive for D. immitis by real-time PCR (3 P. vitulina, 2 Z. californianus and 2 A. p. pusillus), two of which (P. vitulina) were also positive for the nematode's antigen. Additionally, D. immitis microfilariae were detected in one A. p. pusillus. Furthermore, several D. immitis specimens were retrieved from the right ventricle and pulmonary arteries at the necropsy of one $P$. vitulina and one A. p. pusillus.

Conclusions: This study provides new epidemiological data on D. immitis infection in pinnipeds diagnosed through clinical, molecular and pathological findings. Additionally, the South African fur seal is herein reported as a new host for this zoonotic filarioid. The situation herein described could also occur in other parks located in areas where canine dirofilariosis is endemic. Active surveillance and preventive measures of dirofilariosis in pinnipeds on a local and global scale are therefore vital to improve the early diagnosis and control of dirofilariosis.
\end{abstract}

Keywords: Dirofilaria immitis, Pinnipeds, South African fur seal, Dirofilariosis, Vector-borne disease, Wildlife, Zoonosis

\section{Background}

Dirofilaria immitis (Spirurida: Onchocercidae) is a mosquito-borne pathogen spreading worldwide, and the associated infection (i.e. dirofilariosis) is becoming a threat to animals and humans living in endemic areas [1]. Although definitive hosts are primarily domestic and wild canids, Dirofilaria immitis shows low vertebrate host specificity, infecting several mammalian species (e.g. black bears, cats, ferrets, lions, otters, ocelots). In

\footnotetext{
* Correspondence: domenico.otranto@uniba.it

${ }^{\dagger}$ Equal contributors

${ }^{2}$ Università degli Studi di Bari, Bari, Italy

Full list of author information is available at the end of the article
}

humans, this parasite may cause a severe clinical condition of increasing concern, with adult stages located mostly in the patient's lungs, eyes or other anatomical districts [1]. However, little is known about the occurrence and risk of infection of $D$. immitis in pinnipeds. Only a few cases of infection in captive pinnipeds have been described so far [2-7]. Accordingly, no epidemiological studies on pinniped populations are available [8] and adult $D$. immitis have only been found in one hooded seal (Cystophora cristata) [2], one common seal (Phoca vitulina) [3], and in California sea lions (Zalophus californianus) kept in zoological parks in Florida [4], Louisiana [5] and Japan [6]. In the above-mentioned reports, 
nematodes were found upon necropsy in the right ventricle of the heart, pulmonary arteries, vena cavae, portal vein and pericardial sac [3-6]. Clinical signs, only documented in California sea lions, included cardiopulmonary impairment, coughing and laboured breathing $[4,5]$. Indeed, pinnipeds might remain asymptomatic, even when large numbers of parasites inhabit their heart and associated vessels [3-6]. Here we report dirofilariosis in a population of pinnipeds housed at an oceanographic park in Portugal and the South African fur seal, Arctocephalus pusillus pusillus, as a new host for D. immitis.

\section{Methods}

In 2013 and 2014, during the necropsy examinations of two adult South African fur seals (A. p. pusillus) housed at the Zoomarine park in Albufeira (Algarve, southern Portugal), D. immitis nematodes were accidentally found in the pulmonary arteries and right ventricle of two animals (animals A and B). These cases prompted an epidemiological survey to assess the occurrence of $D$. immitis in the park's resident pinniped population $(n=16)$. In 2015, 5 common seals (Phoca vitulina), 2 grey seals (Halichoerus grypus), 3 California sea lions (Zalophus californianus) and 6 South African fur seals (A. p. pusillus) were surveyed for D. immitis infection. All animals were housed in facilities with pools and dry areas and no ecto- or endoparasitic treatments were administered. The animals originated from either Europe or Canada, and remained in Portugal for at least 10 years.

Physical examination was performed to check for the presence of abnormal clinical signs in individual animals. Blood was collected from the epidural intervertebral vein in the phocids ( $P$. vitulina and H. grypus) and from the interdigital vein of the hind flippers or caudal gluteal vein in the otariids (Z. californianus and A. p. pusillus), as previously described [9]. A rapid commercial qualitative antigen WITNESS ${ }^{\circ}$ HW Heartworm Antigen Test Kit (Zoetis, Europe) was used to assess the presence of D. immitis circulating antigens and a modified Knott's technique was performed to detect circulating microfilariae in the pinnipeds' blood. In one of the animals, it was possible to perform an ultrasound to assess the presence of heartworm infection and evaluate cardiac function.

During this epidemiological survey two animals died and necropsies were conducted as described in [10, 11]. Lung and liver samples were collected for histopathological examination, fixed in $10 \%$ buffered formalin and embedded in paraffin; sections ( $3 \mu \mathrm{m}$ thick) were stained with haematoxylin and eosin for routine microscopic examination.

Genomic DNA was extracted from segments (about $10 \mathrm{~mm}$ ) of the adult worms collected from the necropsies and from the 16 blood samples, using a commercial kit (DNeasy Blood \& Tissue Kit, Qiagen, GmbH, Hilden,

Table 1 Test results of the 16 pinnipeds surveyed to Dirofilaria immitis

\begin{tabular}{|c|c|c|c|c|c|c|c|c|}
\hline Animal & Species & Sex & Country of origin & Birth year & Antigen test & Knott test & $\mathrm{qPCR}$ & Signs \\
\hline 1 & P. vitulina & $M$ & Portugal & 2012 & - & - & - & - \\
\hline 2 & P. vitulina & $\mathrm{F}$ & Canada & 1989 & Positive & - & Positive $^{a}$ & - \\
\hline 3 & P. vitulina & M & Canada & 1996 & - & - & - & - \\
\hline 4 & P. vitulina & $\mathrm{F}$ & Portugal & 2007 & - & - & Positive & - \\
\hline 5 & P. vitulina & $\mathrm{F}$ & Canada & 1989 & Positive & - & Positive & - \\
\hline 6 & H. grypus & M & Portugal & 2002 & - & - & - & - \\
\hline 7 & H. grypus & $\mathrm{F}$ & Canada & 1990 & - & - & - & - \\
\hline 8 & Z. californianus & M & Portugal & 1996 & - & - & Positive & - \\
\hline 9 & Z. californianus & M & Spain & 2003 & - & - & - & - \\
\hline 10 & Z. californianus & M & Belgium & 1996 & - & - & Positive & - \\
\hline 11 & A. p. pusillus & M & Portugal & 1998 & - & - & Positive & - \\
\hline 12 & A.p. pusillus & M & UK & 1992 & - & Positive & Positive & $\begin{array}{l}\text { Cough, lethargy and } \\
\text { exercise intolerance }\end{array}$ \\
\hline 13 & A.p. pusillus & M & Sweden & 2002 & - & - & - & - \\
\hline 14 & A. p. pusillus & M & Sweden & 2002 & - & - & - & - \\
\hline 15 & A. p. pusillus & M & Portugal & 1996 & - & - & - & - \\
\hline 16 & A. p. pusillus & M & Spain & 1996 & - & - & - & - \\
\hline Total & & $12 \mathrm{M} / 4 \mathrm{~F}$ & & & 2 & 1 & 7 & - \\
\hline
\end{tabular}

Abbreviations: $F$ female, $M$ male

${ }^{a}$ Animal in which transthoracic echocardiography was performed revealing the presence of linear mobile hyperechoic structures within the right ventricle and main pulmonary artery, consistent with heartworms 


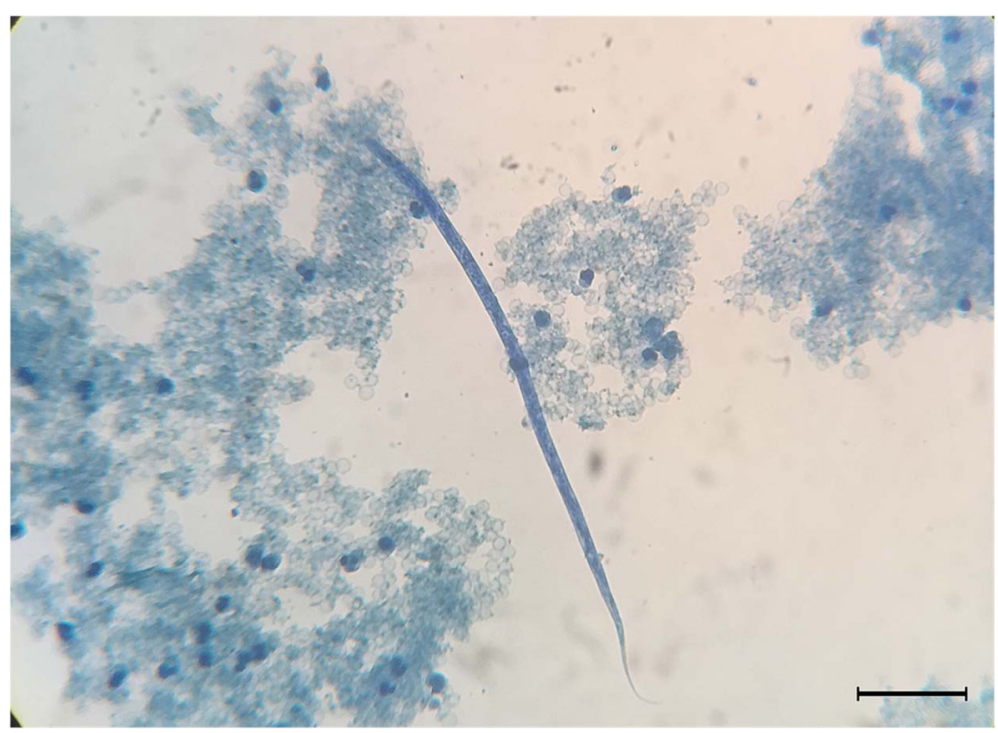

Fig. 1 Microfilaria of Dirofilaria immitis detected using the modified Knott's technique. Scale-bar: $50 \mu \mathrm{m}$

Germany) and tested by real-time PCR (qPCR), based on SsoFast $^{\mathrm{TM}}$ EvaGreen, targeting partial cytochrome $c$ oxidase subunit $1(\operatorname{cox} 1)$, coupled with melting-curve analysis for the detection and discrimination of Dirofilaria spp. [12]. The real-time PCR products were purified using UltrafreeDA columns (Millipore, Bedford, USA), sequenced using BigDye ${ }^{\varpi}$ Terminator v3.1 Cycle Sequencing Kit (Applied Biosystems Inc.) in an automated sequencer (ABI-PRISM 377; Applied Biosystems Inc.). All sequences generated were compared to sequences available in GenBank using Basic Local Alignment Search Tool (BLASTn) [13].

\section{Results}

Two $P$. vitulina were antigen positive $(12.5 \%)$ and one $A$. $p$. pusillus scored positive for $D$. immitis microfilariae $(6.3 \%)$ (Table 1). Circulating microfilariae were 300-305 $\mu \mathrm{m}$ long bearing a conical anterior edge and straight rear end (Fig. 1). Seven (43.8\%) out of the 16 animals were positive for $D$. immitis at qPCR (3 P. vitulina, 2 Z. californianus and 2 A. p. pusillus), with melting peaks (mean $\mathrm{Tm}=75{ }^{\circ} \mathrm{C}$ ) corresponding to the species-specific range of $D$. immitis positive control (mean \pm SD: $75.7 \pm 0.3{ }^{\circ} \mathrm{C}$ ) (Table 1$)$.

One $P$. vitulina (Table 1 , animal no. 5) and one $A . p$. pusillus (Table 1, animal no. 12) died during the study (Table 2). Data from these two animals were gathered with those obtained from animals' A and B dead prior to the epidemiological survey. Overall, during the necropsies of these four animals (A, B, no. 5 and no. 12), adult male and gravid female nematodes were retrieved from the right ventricle and pulmonary arteries (Fig. 2). Macroscopically, lungs were congested and haemorrhagic, and mild right ventricular hypertrophy was noticed. In these four cases, gross and histopathological abnormalities associated with $D$. immitis infection were present, including pulmonary congestion and haemorrhages (Fig. 3), pulmonary emphysema, interstitial and exudative pneumonia, catarrhal bronchitis and hepatic congestion (Table 2, Fig. 4). In the four cases, cardiopulmonary impairment was noticed. The adult nematodes collected from the four individuals were morphologically

Table 2 Data of the four necropsies of seals in which Dirofilaria immitis nematodes were detected

\begin{tabular}{|c|c|c|c|c|c|c|c|}
\hline Animal ID & Species & Sex & Birth year & Death year & $\begin{array}{l}\text { No. of adult } \\
\text { D. immitis }\end{array}$ & $\begin{array}{l}\text { Location of adult } \\
\text { nematodes }\end{array}$ & Pathological observations and histological abnormalities \\
\hline $\mathrm{A}$ & A. p. pusillus & M & 1988 & 2013 & 15 & $\begin{array}{l}\text { Right ventricle and } \\
\text { pulmonary artery }\end{array}$ & $\begin{array}{l}\text { Severe pulmonary hemorrhages; extensive pulmonary } \\
\text { congestion and moderate pulmonary emphysema }\end{array}$ \\
\hline B & A. p. pusillus & M & 1988 & 2014 & 10 & Pulmonary artery & $\begin{array}{l}\text { Moderate interstitial and exudative pneumonia; catarrhal } \\
\text { bronchitis; moderate pulmonary congestion; central lobular } \\
\text { hepatic congestion and dilation of the sinusoids }\end{array}$ \\
\hline 5 & P. vitulina & $\mathrm{F}$ & 1989 & 2016 & 32 & $\begin{array}{l}\text { Right ventricle and } \\
\text { pulmonary artery }\end{array}$ & Extensive pulmonary congestion \\
\hline 12 & A. p. pusillus & M & 1992 & 2016 & 26 & $\begin{array}{l}\text { Right ventricle and } \\
\text { pulmonary artery }\end{array}$ & Extensive pulmonary congestion \\
\hline
\end{tabular}



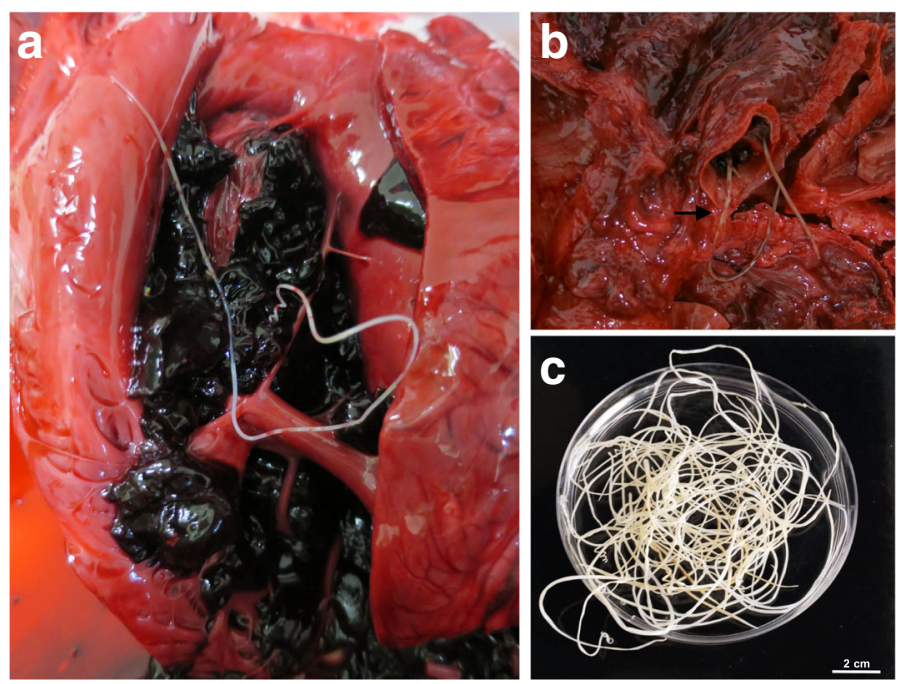

Fig. 2 Adult nematodes of Dirofilaria immitis collected at the necropsies of South African fur seals. a Adult nematode in the right ventricle. $\mathbf{b}$ Adult nematodes (arrow) in the pulmonary artery, showing extensive pulmonary congestion. c Male and female adult nematodes recovered from the blood clot. Scale-bar. $2 \mathrm{~cm}$

and molecularly identified as D. immitis. All cox 1 gene sequences obtained from the adult nematodes and from the pinniped's blood were identical (GenBank accession number KX372755), showing 100\% nucleotide identity to a D. immitis sequence in GenBank (KF553638).

\section{Discussion}

This study provides new epidemiological data of dirofilariosis by $D$. immitis in pinnipeds, diagnosed through clinical, molecular and pathological findings. The South African fur seal is herein described as a new host of $D$. immitis. All animals were housed in a tourist attraction (i.e. an oceanographic park) in the Algarve region, southern Portugal, an area that records the highest

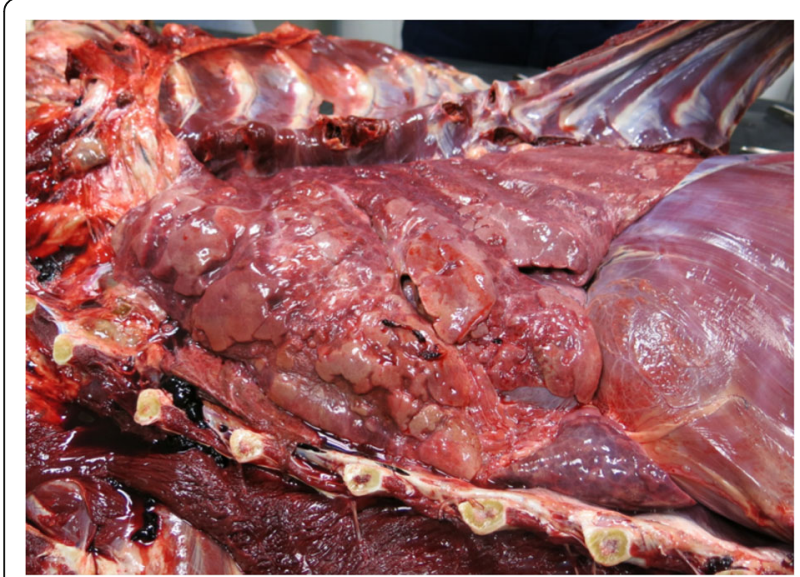

Fig. 3 Macroscopic appearance of the lungs in the necropsy of a South African fur seal, highlighting an extensive pulmonary congestion and pulmonary haemorrhages number of days/year with suitable conditions for Dirofilaria transmission [14], and the highest prevalence of canine dirofilariosis in mainland Portugal [15].

For the first time, qPCR was successfully used to diagnose $D$. immitis infection in pinnipeds. Indeed, $\mathrm{qPCR}$ detected seven infected animals, of which two $P$. vitulina and one $A$. $p$. pusillus which were also positive for circulating antigen and microfilariae, respectively. GPCR was highly sensitive in diagnosing $D$. immitis in pinnipeds, since it was able to detect one animal that was only antigen-positive (no. 5) and another that was onlymicrofilaremic (no. 12), although both presented several nematodes (including gravid females) during the necropsy. In addition, it detected also another case (animal no. 2) only positive for the antigen, but in which transthoracic echocardiography revealed linear hyperechoic structures consistent with heartworms within the right ventricle and main pulmonary arteries. Furthermore, qPCR was also able to detect four other animals that were negative in all other diagnostic tests used (microfilariae and/or antigen; Table 1). All pinnipeds were retested by modified Knott's technique and antigen test to rule out potential false negatives. These further analyses displayed identical results. Positivity to $\mathrm{qPCR}$ suggests that alive parasites have been in contact with pinnipeds with no information on the current infection status. Indeed, this molecular assay may detect $D$. immitis DNA from a current infection or, theoretically, from a recently cleared infection. In addition, dirofilariosis in pinnipeds may be featured by transient and low intensity microfilaremia, as in the case of infection in cats. This might be the reason for the detection of microfilaremia in only one of the two pinnipeds who had male and 


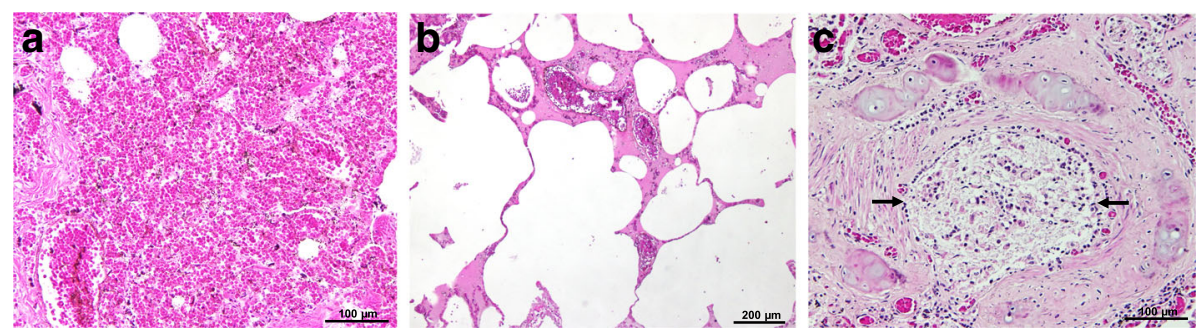

Fig. 4 Histopathology of the lungs of a South African fur seal, stained with haematoxylin and eosin. a Severe pulmonary haemorrhages, note the presence of blood in the lumen of the alveoli. b Extensive pulmonary emphysema. c Catarrhal bronchitis, note the lumen of a bronchus obstructed with mucus (arrows)

female nematodes at necropsies. Additionally, rapid commercial D. immitis antigen tests were specifically developed for canine and feline blood samples, thus, their sensitivity and performance might be poor when used in pinnipeds, underestimating the true prevalence.

Although pinnipeds are aquatic mammals, they spend large periods of their life in terrestrial environments, and are therefore exposed to mosquito bites. As in the present survey, D. immitis could also occur in other parks in countries with endemic areas for canine dirofilariosis. The occurrence of this situation in the Algarve region, a popular summer destination, should be carefully considered due to the zoonotic potential of this parasite. Indeed, although human dirofilariasis has been often underdiagnosed (probably due to the lack of awareness amongst health professionals and to the difficulties in parasite identification), two cases of pulmonary nodules by $D$. immitis [16] and two cases of subcutaneous dirofilariasis by Dirofilaria repens $[17,18]$ have already been reported in Portugal.

\section{Conclusions}

This study emphasizes the need for active surveillance of dirofilariosis in facilities where animals and humans are in close contact, and strengthens the need for routine heartworm preventive measures [19] and vector control strategies. The high prevalence of $D$. immitis herein reported in a confined area where pinnipeds are kept, may represent a risk interface for zoonotic pathogen transmission. Therefore, a One Health approach applied on a local and global scale [20] is vital to improve early diagnosis and control of zoonotic pathogens in humans and wildlife.

\section{Abbreviation}

qPCR: real-time PCR

\section{Acknowledgments}

The authors are grateful to Mundo Aquático S.A. - Zoomarine and to Fundação para a Ciência e a Tecnologia. Publication of this paper has been sponsored by Bayer Animal Health in the framework of the 12nd CVBD World Forum Symposium

\section{Funding}

This study was financially supported by Fundação para a Ciência e a Tecnologia (FCT), through a PhD research grant SFRH/BD/85427/2012 and by the Project UID/CVT/00276/2013. The funder had no role in the design of the study, collection, analysis, interpretation of data or in writing the manuscript.

\section{Availability of data and materials}

All data generated or analysed during the study are included in the article.

\section{Authors' contributions}

AMA and IM conceived the study, performed morphological and serological analysis and drafted the manuscript; VC performed morphological and molecular analysis and drafted the manuscript; CF and NS conducted clinical examination, sample collection and necropsies; JJC performed histopathological analysis; MSL performed molecular and data analysis; DO analysed data and revised the manuscript; LMC conceived the study and reviewed the manuscript. All authors read and approved the final manuscript.

\section{Competing interests}

The authors declare that they have no competing interests.

\section{Consent for publication}

Not applicable.

\section{Ethics approval}

All technical procedures were reviewed and approved by Zoomarine's Ethical and Animal Welfare Committee. The protocol was performed in accordance to the standards and guidelines of the Alliance of Marine Mammal Parks and Aquariums (AMMPA) and European Association of Aquatic Mammals (EAAM), and to the National legislation regarding animal welfare (DL 276/2001 and DL 314/2003).

\section{Author details}

'CIISA, Faculdade de Medicina Veterinária, Universidade de Lisboa (ULisboa), Lisboa, Portugal. ${ }^{2}$ Università degli Studi di Bari, Bari, Italy. ${ }^{3}$ Mundo Aquático S.A. Zoomarine, Albufeira, Portugal.

Received: 29 December 2016 Accepted: 28 February 2017 Published online: 13 March 2017

\section{References}

1. Simón F, Siles-Lucas M, Morchón R, González-Miguel J, Mellado I, Carretón E, et al. Human and animal dirofilariasis: the emergence of a zoonotic mosaic. Clin Microbiol Rev. 2012;25:507-44.

2. King JE. Seals of the world. London: British Museum of Natural History; 1964.

3. Medway W, Wieland TC. Dirofilaria immitis infection in a harbor seal. J Am Vet Med Assoc. 1975;167:549-50.

4. Forrester DJ, Jackson RF, Miller JF, Townsend BC. Heartworms in captive California sea lions. J Am Vet Med Assoc. 1973;163:568-70.

5. White GL. Dirofilaria immitis and heartworm disease in the California sea lion. J Zoo Anim Med. 1975;6:23-4.

6. Sato T, Higuchi T, Shibuya H, Ohba S, Nogami S, Shirai W, et al. Lingual squamous cell carcinoma in a California sea lion (Zalophus californianus). J Zoo Wildl Med. 2002;33:367-70. 
7. Van Bonn WG. Pinnipedia. In: Miller RE, Fowler ME, editors. Fowler's zoo and wild animal medicine. Missouri: Elsevier Saunders; 2015. p. 436-49.

8. Krucik DD, Van Bonn W, Johnson SP. Association between positive canine heartworm (Dirofilaria immitis) antigen results and presence of Acanthocheilonema odendhali microfilariae in california sea lions (Zalophus californianus). J Zoo Wildl Med. 2016;47:25-8.

9. Gulland FMD, Haulena M, Dierauf LA. Seals and sea lions. In: Dierauf LA, Gulland FMD, editors. CRC handbook of marine mammal medicine. 2nd ed. Boca Raton: CRC Press; 2001. p. 791-827.

10. Geraci JR, Lounsbury VJ. Marine mammals ashore: a field guide for strandings. 2nd ed. Baltimore: National Aquarium in Baltimore; 2005

11. Pugliares KR, Bogomolni A, Touhey KM, Herzig SM, Harry CT, Moore MJ. Marine mammal necropsy: an introductory guide for stranding responders and field biologists. 2007.

12. Latrofa MS, Dantas-Torres F, Annoscia G, Genchi M, Traversa D, Otranto D. A duplex real-time polymerase chain reaction assay for the detection of and differentiation between Dirofilaria immitis and Dirofilaria repens in dogs and mosquitoes. Vet Parasitol. 2012;185:181-5.

13. Altschul SF, Madden TL, Schäffer AA, Zhang J, Zhang Z, Miller W, et al. Gapped BLAST and PSI-BLAST: a new generation of protein database search programs. Nucleic Acids Res. 1997;25:3389-402.

14. Alho AM, Nunes T, Rinaldi L, Meireles J, Belo S, Deplazes P, et al. Transmission risk of dirofilariosis in Portugal. Parasit Vectors. 2014;7 Suppl 1:016.

15. Cardoso L, Mendão C, Madeira de Carvalho L. Prevalence of Dirofilaria immitis, Ehrlichia canis, Borrelia burgdorferi sensu lato, Anaplasma spp. and Leishmania infantum in apparently healthy and CVBD-suspect dogs in Portugal-a national serological study. Parasit Vectors. 2012;5:62.

16. Araújo AM. Canine and human Dirofilaria immitis infections in Portugal. A review. Parassitologia. 1996;38:366.

17. Rombert PC, Nunes J, Azevedo V, Sinari V. Um caso de dirofilariose ocular. 1as Jornadas de Doenças Infecciosas e de Medicina Tropical. Lisboa: Instituto de Higiene e Medicina Tropical; 1992. p. 17.

18. Baptista-Fernandes T, Rodrigues $M$, Domingues D, Monteiro L, Paixão P, Pereira $P$, et al. Dirofilariasis by Dirofilaria repens: an imported case and a brief review. Parasitol Int. 2015;64:261-3.

19. Otranto D, Dantas-Torres F, Brianti E, Traversa D, Petrić D, Genchi C, et al. Vector-borne helminths of dogs and humans in Europe. Parasit Vectors. 2013;6:16.

20. Schwind JS, Goldstein T, Thomas K, Mazet JA, Smith WA, PREDICT Consortium. Capacity building efforts and perceptions for wildlife surveillance to detect zoonotic pathogens: comparing stakeholder perspectives. BMC Public Health. 2014;14:684.

\section{Submit your next manuscript to BioMed Central and we will help you at every step:}

- We accept pre-submission inquiries

- Our selector tool helps you to find the most relevant journal

- We provide round the clock customer support

- Convenient online submission

- Thorough peer review

- Inclusion in PubMed and all major indexing services

- Maximum visibility for your research

Submit your manuscript at www.biomedcentral.com/submit

) Biomed Central 